\title{
NORUS
}

ISSN: $2318-1966$

v. 4 , n. 6

jul - dez 2016

Dossiê

\section{FORMULAÇÕES TEÓRICO- METODOLÓGICAS DE PLANEJAMENTO URBANO SOB A INSPIRAÇÃO DE HENRI LEFEBVRE}

\author{
Márcia Oliveira Kauffmann ${ }^{1}$ \\ Doutora em Planejamento Urbano e Regional (IPPUR/UFRJ) \\ Mauro Kleiman ${ }^{2}$ \\ Professor Titular da Universidade Federal do Rio de Janeiro (IPPUR/UFRJ
}

\begin{abstract}
RESUMO
O forte crescimento e adensamento de construções e de população, impactantes ao meio ambiente, com consequências inclusive em inundações, muitas vezes decorrentes da impermeabilização dos solos, têm marcado os grandes centros urbanos. Discutem-se alternativas teóricas que inspiradas em Henri Lefebvre possam enfrentar estas questões e reformular o planejamento contemporâneo que, calcado em visão dualista da realidade, considera etapas estanques e excludentes na formação e desenvolvimento das cidades, deixando de observar dialeticamente as contradições e tensões entre os diversos polos de oposição presentes nesta dinâmica. A reflexão sobre os caminhos entre a cidade formal e a informal, entre a insustentável e a sustentável, em processo de constante transformação e interação, pode apontar estratégias para a superação dessa dicotomia. A adoção da bacia hidrográfica como unidade de gestão e integração entre os planejamentos urbano, ambiental e de recursos hídricos, associada ao indicador de ocupação sustentável da bacia hidrográfica (IOS-BH), conforme no presente texto, se qualificam como importantes recursos para um novo aporte teóricometodológico em planejar as cidades. Este novo indicador, exemplificado em estudo de caso na cidade do Rio de Janeiro, em forte conexão com a matriz de planejamento, se aplica à legislação urbanística, agrega parâmetros relacionados aos recursos hídricos, urbanos e ambientais e, sobretudo, se constitui em elemento mediador entre as diversas polaridades do contexto urbano, confere retratos da sustentabilidade urbana e instrumentaliza projetos das recuperações necessárias, trazendo à luz o pensamento de Lefebvre também aplicado a novas formulações de indicadores.
\end{abstract}

Palavras-chave: Teorias de Planejamento Urbano; Henri Lefebvre; Sustentabilidade Urbana; Indicadores Urbanos; Planos de Bacias Hidrográficas Urbanas.

\footnotetext{
${ }^{1}$ Doutora em Planejamento Urbano e Regional no Instituto de Pesquisa e Planejamento Urbano e Regional da Universidade Federal do Rio de Janeiro, IPPUR/UFRJ.

${ }^{2}$ Doutor em Arquitetura e Urbanismo pela Universidade de São Paulo. Professor Titular da Universidade Federal do Rio de Janeiro na unidade Instituto de Pesquisa e Planejamento Urbano e Regional (IPPUR-UFRJ).
} 


\title{
THEORETICAL AND METHODOLOGICAL URBAN PLANNING FORMULATIONS INSPIRED BYHENRI LEFEBVRE
}

\begin{abstract}
The strong growth and density of construction and population have greatly impacted the environment. The consequences, including floods that have often stemmed from soil sealing, have marked the great urban centers dramatically. We will discuss theoretical alternatives inspired by Henri Lefebvre which can address these issues and reshape contemporary planning. Current approaches tend to be based on a dualistic view of reality. City formation and development are explained by rigidly defined, discrete stages that fail to describe the contradictions and tensions between various opposing poles within this dynamic. Reflection on the paths between formal and informal cities, between the unsustainable and sustainable, as a process of constant change and interaction, may lead to strategies that overcome this dichotomy. The adoption of the river basin as a management unit and integration between urban, environmental and water resources planning, associated with the Indicator of Sustainable Urban Watershed Occupation (IOS-BH), cited in this text, qualify as important resources for a new theoretical and methodological support in city planning. This new indicator, exemplified in a case study of the city of Rio de Janeiro in strong connection with the planning matrix, applies to planning legislation, adds parameters related to water, urban and environmental resources, and, above all, constitutes a mediating element between the various polarities within the urban context. It presents a portrait of urban sustainability and instrumentalizes necessary recovery projects, while highlighting the thought of Lefebvre in the formulations of new indicators for urban planning.
\end{abstract}

Keywords: Urban Planning Theory; Henri Lefebvre; Urban Sustainability; Urban Indicators; Urban Watershed Plans.

\section{Contexto urbano atual: um caminho para "Trantor"?}

O comprometimento da qualidade de vida especialmente nos grandes centros urbanos se evidencia cada vez mais na concentração, densificação e verticalização das cidades, na urbanização intensiva e extensiva em escala global.

Estas contradições exemplificam-se no Brasil. O último censo, de 2010, apurou que cerca de $84 \%$ da população era urbana e registrou um aumento de 3\% em relação ao ano de 2000 (IBGE, 2013). Recentes publicações registram ainda que em mais de 1.500 municípios do país a proporção de moradores de apartamentos nas cidades quase dobrou na última década e continua aumentando. Aumentam também as temperaturas (em cerca de 5 a 8 graus) principalmente nas áreas com padrão construtivo mais adensado e mais verticalizado (AZEVEDO, 2013) com sérias consequências na redução de ventilação (especialmente dos ventos vindos do oceano no caso das cidades litorâneas); no congestionamento do trânsito e circulação de veículos; no abastecimento de água; no destino dos esgotos e lixo; no aumento da taxa de impermeabilização dos solos, acarretando fortes impactos ambientais inclusive inundações urbanas. 
NORUS - v4, n.6, jul - dez 2016.

Lewis Mumford (1945) vislumbrava as metrópoles e megalópoles já, em meados do século XX, como futuras cidades globais decadentes sob a influência do mito capitalista, concentradas nos negócios e no poder; destacando de forma talvez pioneira o papel dos serviços de infraestrutura nesta dinâmica e relacionando os processos de formação e agravamento da aglomeração urbana ao alerta dramático de possível extinção da civilização.

Este tipo acirrado de crescimento e de concentração urbanos em escala planetária, alinhados com a estratégia do planejamento urbano contemporâneo, a despeito do evidente caráter de insustentabilidade, traz em si como paradoxo as vantagens econômicas, intra e interurbanas, nos investimentos, relacionamentos, competições e outras, inerentes ao próprio desenvolvimento capitalista, mas, sobretudo no contexto da globalização. O limite do contorno da cidade tradicional foi sendo ampliado pelo advento da cidade industrial, pela produção capitalista industrial derramando suas cadeias geográficas e temporais, pelo desenvolvimento de novos modos de transporte, pela invenção e reinvenção de novas tecnologias, produtos e infraestrutura. Inicialmente de espaços absolutos, as cidades tornaram-se espaços relativos, espaços relativos uns aos outros, o que significou, já na segunda metade do século XX, uma hierarquização mundial destas cidades, ditada pela vantagem econômica comparativa (MERRIFIELD, 2013). Este histórico deslocar do absoluto para o relativo preocupa Lefebvre especialmente em La Révolution Urbaine (1970) e em The Production of Space (1991).

Em Le Droit à la Ville, Henri Lefebvre (1968) alude à ficção científica de Isaac Asimov, reconhecendo o germe de "Trantor" no mundo real. "Trantor" um planeta de 40 milhões de habitantes no qual a urbanização atingiu seu máximo absoluto e todos os 75 milhões de quilômetros quadrados de sua superfície são uma única cidade. Também em La Révolution Urbaine (LEFEBVRE, 1970), o mestre dos estudos urbanos marxistas sugere uma nova realidade, não só de sociedade urbana, mas de urbanização planetária. Lefebvre aponta, entretanto, para a construção de um novo modelo de urbanização, orientado para a reapropriação coletiva e autogestão democrática do espaço planetário como trabalho da espécie humana.

Já estava então colocado o desafio da superação da insustentabilidade urbana, hoje pauta na ampla maioria das discussões contemporâneas e que, sob a ótica do pensamento lefebvreano, se relaciona dialeticamente com a sustentabilidade. Na verdade, o conceito de desenvolvimento sustentável desde a conferência ambiental das Nações Unidas realizada em Estocolmo, em 1972, foi sendo contemplado nos primeiros marcos regulatórios, inicialmente de caráter restritivo e preventivo, mais político e social na década de 1980 e, especialmente a partir do 


\section{Formulações teórico-metodológicas de planejamento urbano sob a inspiração de Henri Lefebvre}

final da primeira década do século XXI, com o agravamento da crise econômica mundial, atingiu o patamar da globalização.

Nesta escala, o desenvolvimento sustentável territorial depende da sua capacidade de adaptação face às grandes tendências evolutivas de viés econômico, social, ambiental, político ou tecnológico, segundo a perspectiva da resiliência estratégica. A construção de territórios mais resilientes começa a surgir como tema de investigação científica, como orientação de política e planejamento (SRHU/MMA, 2012). Cidades resilientes ${ }^{3}$ seriam então cidades preparadas para lidar com o não equilíbrio, com o equilíbrio instável; com capacidade de absorver perturbações e se reorganizar, enquanto estão sujeitas a forças de mudança, sendo capazes de manter o essencial das suas funções, estrutura, identidade e mecanismos (CARPENTER et al. 2001; GUNDERSON, HOLLING, 2002; SANTOS, 2009; WALKER et al., 2004).

Em outras palavras resiliência urbana poderia ser considerada como o estado de mediação entre a sustentabilidade e a insustentabilidade das cidades, que reuniria estratégias para a superação e reversão do caminho para "Trantor". Inserido nesta perspectiva o presente texto apresenta uma contribuição teórico-metodológica de inspiração em Henri Lefebvre aplicada ao planejamento urbano buscando a sua superação.

\section{Reflexões para superação do planejamento urbano contemporâneo}

O resgate histórico da construção das cidades contemporâneas permite considerar os diversos pensamentos e contradições que foram impressos e expressos no território por diversos modelos de planejamento, iluminando o atual quadro de insustentabilidade urbana.

A ausência de regras capazes de normatizar os crescentes conflitos urbanos da cidade capitalista, nascida da incipiente estrutura feudal, começou a apontar para a necessidade de intervenção do Estado, tanto na economia como no planejamento da cidade. Nesta perspectiva, o século XIX assiste às diversas intervenções sanitaristas imbuídas do germe da matriz de planejamento que vai permanecer predominante até a atualidade. A desordem, a sujeira e a mistura de classes cederam lugar à ordem, lema essencial de uma nova classe, a burguesia, em

\footnotetext{
${ }^{3}$ Objetivamente podem se destacar alguns aspectos de abordagem fundamentais na concepção das cidades resilientes: multifuncionalidade (a partir da rua); redundância e modularização (distribuição dos riscos com segurança para falhar, uso de áreas inundáveis, distribuição por módulos); biodiversidade; redes verdes e conectividades multiescalares; construção e capacidade adaptativa; utilização de corredores verdes, telhados verdes, jardins suspensos, jardins de chuva, bacias de captação, de retenção de águas pluviais, de decantação, buscando o entrosamento e interligação da rua, casa e áreas de lazer; integração dos planejamentos urbano, ambiental e de recursos hídricos; adoção de metodologias alternativas de desenvolvimento urbano de baixo impacto (CARPENTER et al., 2001; GUNDERSON, HOLLING, 2002; SANTOS, 2009; WALKER et al., 2004).
} 
NORUS - v4, n.6, jul - dez 2016.

ascensão, que busca imprimir sua marca na cidade, através de uma nova estética da beleza, mas também de ordem. Esta visão expressa a mudança de entendimento de um universo estático para um universo dinâmico, mas com leis e ordem, pensamento central do planejamento que, já ao início do século passado, se volta ao futuro, para o desenvolvimento, matriz do planejamento racional-funcionalista que se inicia então.

A cidade passa a se destinar ao indivíduo-tipo buscando atender às necessidades de habitar, entreter, locomover e trabalhar. Os protótipos de escolas e habitações são respostastipo que atendem às demandas da industrialização e estandardização crescentes. As zonas estanques e articuladas pelo automóvel encobrem as classes sociais que usarão a cidade de forma diferenciada. O território definido a partir do viés físico, através do desenho e redesenho da cidade, intensifica a compartimentação definida tecnicamente (KLEIMAN et al., 2006, NACIF XAVIER, 2002 apud KAUFFMANN LEIVAS, 2011).

Ao início do século XXI as críticas ao modelo funcionalista vão configurando nova formulação urbana com a adoção de funções e usos misturados, sem espaços verdes e sem longos deslocamentos, na busca do retorno à cidade mista. Intensificam-se os centros e sub centros, o espessamento por densificação e verticalização (KLEIMAN et al., 2006; FREITAS RIBEIRO, 2009), inspirando o planejamento estratégico.

Para o caso do Brasil, o modelo de planejamento estratégico é importado, mas se mantém o papel centralizador do Estado ao lado das empresas que buscam na descentralização dos investimentos, na flexibilização em intervenções pontuais o atendimento dos seus interesses. Incorpora práticas empresariais no sentido da produtividade urbana, mas convive com as contradições entre esta flexibilização e a rigidez do planejamento racional-funcionalista consolidada no zoneamento e na legislação urbanística em vigor. Baseado na ideia, resgatada do planejamento racional-funcionalista, de que o desenho físico é capaz de formatar a vida, o planejamento estratégico, com a visão ampliada de cidade articulada em polos de atração, vai criar descontinuidades e acentuar as já existentes. (KLEIMAN et al., 2006) ${ }^{4}$. Além destas contradições o planejamento urbano no Brasil cada vez mais se confrontou com a necessidade de sua compatibilização com a gestão ambiental e de recursos hídricos, alternativa desejável à construção da sustentabilidade.

\footnotetext{
${ }^{4}$ Especialmente no Rio de Janeiro destaca-se a convivência, já na década de 90, destes dois modelos de planejamento: o racional-funcionalista (Plano Diretor Decenal da Cidade do Rio de Janeiro aprovado em 1992) e o estratégico (Plano Estratégico I - Rio Sempre Rio de 1992). Ambos revistos em Plano Diretor de Desenvolvimento Urbano Sustentável do Município do Rio de Janeiro, aprovado em 2011 e Plano Estratégico da Prefeitura do Rio de Janeiro 2009-2012 - O Rio mais Integrado e Competitivo, caracterizando com esta concomitância, peculiarmente, as contradições e constantes tensões do planejamento contemporâneo nas tentativas de compatibilizar modelos e estratégias tão diferenciadas (KAUFFMANN LEIVAS, KLEIMAN, 2013).
} 


\section{Formulações teórico-metodológicas de planejamento urbano sob a inspiração de Henri Lefebvre}

Especificamente tratando-se das águas urbanas vale um rápido resgate dos modelos de drenagem que, em certa medida se relacionam aos modelos de planejamento urbano (CERQUEIRA, 2012; KAUFFMANN LEIVAS, 2011; KLEIMAN, KAUFFMANN, 2008; POLETO, 2011).

A perspectiva higienista (século XIX) que adotava intervenções pontuais sem articulação com os impactos urbanos: drenagem rápida; redes subterrâneas e canalização de cursos d'água naturais; sistema de drenagem e viário associados, pode se corresponder ao modelo sanitarista caracterizado pela busca da salubridade em intervenções pontuais na cidade: aterros e arrasamentos de morros e habitações; alargamento de ruas em avenidas; sob a perspectiva da estética e da ordem. A preservação do meio ambiente na ocupação urbana, naquele momento, ainda não estava colocada.

No século XX o modelo de drenagem urbana corretivo ou racionalista no qual se enfatizavam a utilização de técnicas compensatórias por meio de mecanismos de amortecimento; manejo eficiente do quantitativo das águas pluviais e busca por superação das cheias e controle das inundações urbanas, se relaciona ao modelo racional-funcionalista de planejamento urbano no qual se identificam o uso de ferramentas gerais para a cidade, inclusive o zoneamento norteador do uso e ocupação do solo que, sob a ordem e a eficiência, trata a cidade em partes. Nesta época já se notam avanços na legislação por gestão urbana mais democrática e articulada aos recursos ambientais.

A atualidade (século XXI) é marcada pela busca da integração urbana e ambiental na perspectiva da sustentabilidade. Em drenagem urbana configuram-se metodologias alternativas de conservação dos recursos naturais: renaturalização do meio urbano, captação das águas pluviais na fonte, reuso, infiltração e amortecimento; uso de áreas verdes e parques lineares associados à preocupação com os impactos urbanos. Em planejamento urbano, com o agravamento das tensões e contradições urbanas; coexistência do Planejamento Funcionalista (geral) com o Estratégico (local), criam-se centralidades buscando atrair investimentos em reforço da imagem competitiva da cidade no mercado mundial.

Como expectativas para um futuro próximo, nos planejamentos urbano, ambiental e de recursos hídricos, considera-se fortemente a sua integração, como condição necessária para a superação das dicotomias contemporâneas, apoiada em metodologias alternativas de 
urbanização de baixo impacto, em recursos na legislação em vigor ${ }^{5}$, instrumentos e estratégias, em especial a adoção da bacia hidrográfica ${ }^{6}$ como unidade desta gestão articulada.

Entretanto a despeito desta intenção, na prática, esta integração ainda encontra entraves, até mesmo na viabilização da sua unidade integrada de planejamento, mesmo já sendo proposição considerada desde as formulações do início do século XVII, conforme se apresenta no Quadro 1, adiante.

\section{Quadro 1 - Exemplos na Evolução da Gestão Urbana e das Águas por Bacia Hidrográfica}

\begin{tabular}{|c|c|c|}
\hline Época & $\begin{array}{c}\text { Autor/ } \\
\text { Referência }^{7}\end{array}$ & Comentários \\
\hline 1616 & $\begin{array}{l}\text { GRANZIERA, } \\
2001 ; \text { GRIGG, } \\
1991\end{array}$ & $\begin{array}{l}\text { Tratados de utilização do Rio Danúbio com recorte territorial nas bacias } \\
\text { hidrográficas. }\end{array}$ \\
\hline 1851 & $\begin{array}{l}\text { GRANZIERA, } \\
2001 ; \text { GRIGG, } \\
1991\end{array}$ & $\begin{array}{l}\text { Tratado Brasil-Peru sobre a navegação do Rio Amazonas considerando as } \\
\text { bacias e sub bacias hidrográficas. }\end{array}$ \\
\hline $\begin{array}{l}1904 / \\
1994\end{array}$ & $\begin{array}{l}\text { GEDDES, 1904; } \\
1994\end{array}$ & $\begin{array}{l}\text { Desenvolveu o conceito de região natural: exemplo a sua famosa seção de } \\
\text { vale: "a perspectiva clara, a visão mais panorâmica de uma determinada } \\
\text { região geográfica [...] assim também uma bacia hidrográfica é, [...] um item } \\
\text { essencial para o estudioso de cidades e civilizações [...]" (HALL, 2005, } \\
\text { p162). }\end{array}$ \\
\hline $\begin{array}{l}\text { Final da } \\
\text { década de } \\
1900\end{array}$ & $\begin{array}{l}\text { MUMFORD apud } \\
\text { HALL, } 2005\end{array}$ & $\begin{array}{l}\text { Um dos fundadores da Regional Planning Association of America, deu } \\
\text { prosseguimento aos estudos de Geddes acerca do planejamento regional } \\
\text { (HALL, 2005). }\end{array}$ \\
\hline 1912 & $\begin{array}{l}\text { KRAEMER, } \\
\text { JÄGER, } 1998\end{array}$ & Agência do Rhur na Alemanha. \\
\hline 1922 & $\begin{array}{l}\text { GRANZIERA, } \\
2001 ; \text { GRIGG, } \\
1991\end{array}$ & $\begin{array}{l}\text { Pacto do Rio Colorado nos Estados Unidos. Tratando da partição da } \\
\text { utilização da água do rio entre os Estados que compartilhavam a sua bacia } \\
\text { hidrográfica. }\end{array}$ \\
\hline 1928 & $\begin{array}{l}\text { GRANZIERA, } \\
2001 ; \text { GRIGG, } \\
1991\end{array}$ & $\begin{array}{l}\text { Tratado entre o Brasil e a República das Províncias Unidas do Rio da Prata } \\
\text { com recorte territorial nas bacias hidrográficas. }\end{array}$ \\
\hline 1933 & LLIENTHAL, 1972 & $\begin{array}{l}\text { Formação do Tennessee Valley Authority - TVA (Autarquia do Vale do } \\
\text { Tennessee). Exerceu forte influência no Brasil, e em diversos países. } \\
\text { Tornou-se um símbolo do desenvolvimento unificado de recursos. }\end{array}$ \\
\hline
\end{tabular}

\footnotetext{
${ }^{5}$ Ver KAUFFMANN LEIVAS, 2011.

${ }^{6}$ Bacia hidrográfica define a área topograficamente drenada por um curso d'água ou por um sistema interligado de cursos d'água de tal forma que todos os caudais efluentes sejam descarregados através de uma única saída. Os seus terrenos são delimitados por dois tipos de linhas de separação de águas: uma topográfica ou superficial outra freática ou subterrânea. A área da bacia é chamada área de drenagem ou de contribuição, normalmente medida em quilômetros quadrados (COSTA, 2001 apud KAUFFMANN LEIVAS, 2011; WEBER, 2001 apud KAUFFMANN LEIVAS, 2011). As bacias hidrográficas urbanas são as significativamente povoadas, ocupadas pela expansão da malha urbana das cidades. São áreas que, apresentam atividades humanas concentradas, com ocupação do solo impermeabilizando extensas áreas e cursos d'água canalizados e alterados por intervenção do homem.

${ }^{7}$ Referências em KAUFFMANN LEIVAS, 2011.
} 


\section{Lefebvre}

\begin{tabular}{|c|c|c|}
\hline $\begin{array}{l}\text { Final da } \\
\text { década de } \\
1940\end{array}$ & $\begin{array}{l}\text { KLEIMAN, } \\
\text { KAUFFMANN, } \\
2006\end{array}$ & $\begin{array}{l}\text { Comissão do Vale do São Francisco que se destinava a uma bacia } \\
\text { envolvendo seis estados e o Distrito Federal. Experiência inspirada na TVA. }\end{array}$ \\
\hline $1964 / 1992$ & SILVA, 1998 & $\begin{array}{l}\text { Na França a Lei das Águas de } 1964 \text { estabeleceu a luta contra a poluição das } \\
\text { águas, sua regeneração, seu regime e distribuição e a Lei Complementar de } \\
1992 \text { unificou as ações estatais e estendeu o conceito de bem público para } \\
\text { as águas superficiais e subterrâneas. O sistema hídrico foi dividido em seis } \\
\text { bacias, e constituído por Comitês de Bacia; Agências de Água e } \\
\text { coordenação do Prefeito. Este modelo francês influenciou fortemente a } \\
\text { legislação brasileira. }\end{array}$ \\
\hline 1968 & $\begin{array}{l}\text { KENNEWEG, } \\
2005\end{array}$ & $\begin{array}{l}\text { Carta Europeia da Água cujo principal princípio era que "a água não } \\
\text { reconhece fronteiras". }\end{array}$ \\
\hline 1972 & COELHO, 2004 & $\begin{array}{l}\text { Florida Water Resources Act, EUA. Dividiu o Estado da Flórida em cinco } \\
\text { distritos de gerenciamento de água (delimitados por bacias hidrográficas) } \\
\text { com a responsabilidade pela regulamentação, cobrança, organização, } \\
\text { monitoramento e manejo dos recursos hídricos. }\end{array}$ \\
\hline $\begin{array}{ll}\text { Final da } & \\
\text { década } & \text { de } \\
1970 & \end{array}$ & $\begin{array}{l}\text { KLEIMAN, } \\
\text { KAUFFMANN, } \\
2006\end{array}$ & $\begin{array}{l}\text { Surgem os primeiros comitês de bacias no Brasil, em 1978, criou-se o } \\
\text { Comitê Especial de Estudos Integrados de Bacias Hidrográficas (CEEIBH). } \\
\text { Surgem vários Planos Diretores Municipais (da década de } 1970 \text { até a década } \\
\text { de 1990) nos moldes racionalistas de planejamento, nos quais se nota a } \\
\text { preocupação com o planejamento urbano integrado ao de recursos hídricos. }\end{array}$ \\
\hline $\begin{array}{ll}\text { Final da } \\
\text { década } \\
1980\end{array}$ & $\begin{array}{l}\text { KAUFFMANN } \\
\text { LEIVAS, } 2011\end{array}$ & $\begin{array}{l}\text { Promulgada no Brasil a Constituição de } 1988 \text { que incluiu avanços na gestão } \\
\text { urbana articulada com os recursos hídricos. }\end{array}$ \\
\hline $\begin{array}{ll}\text { Final da } & \\
\text { década } & \text { de } \\
1990 & \end{array}$ & ANA, 2011 & $\begin{array}{l}\text { Crescem os comitês de bacias no Brasil. Promulgada a Lei das Águas, Lei } \\
9.433 / 97 \text { que instituiu as Agências de Águas; o Sistema Nacional de } \\
\text { Gerenciamento de Recursos Hídricos (SNGRH), cujo Conselho Nacional de } \\
\text { Recursos Hídricos (CNRH) decide sobre a criação de comitês de bacias em } \\
\text { rios de domínio da União. A bacia hidrográfica se consolida como a unidade } \\
\text { de planejamento dos recursos ambientais, culturais, históricos e } \\
\text { urbanísticos. }\end{array}$ \\
\hline $\begin{array}{l}1997 \\
/ 2002\end{array}$ & CORREIA, 1998 & $\begin{array}{l}\text { WATER } 21 \text { projeto, inserido no Programa de Pesquisa em Meio Ambiente } \\
\text { (Environmental Research Program) da União Europeia com objetivo de } \\
\text { avaliar políticas de água sob a perspectiva da sustentabilidade, identificar os } \\
\text { desvios, propor mudanças e discutir as diversidades. }\end{array}$ \\
\hline 2000 & ANA, 2011 & $\begin{array}{l}\text { A Agência Nacional das Águas - ANA, responsável pela implantação da } \\
\text { Política Nacional de Recursos Hídricos no Brasil, foi regulamentada na Lei } \\
9.984 / 2000 \text {. }\end{array}$ \\
\hline 2001 & $\begin{array}{l}\text { KAUFFMANN } \\
\text { LEIVAS, } 2011\end{array}$ & $\begin{array}{l}\text { Estatuto da Cidade, Lei 10.257/2001. Diretrizes gerais para a política urbana } \\
\text { no Brasil; a função social da propriedade urbana; os Planos Diretores, na } \\
\text { garantia da Gestão Democrática das Cidades. Avança na direção da } \\
\text { integração dos planejamentos urbano e de recursos hídricos. }\end{array}$ \\
\hline $\begin{array}{l}\text { A partir da } \\
\text { década de } \\
2000\end{array}$ & $\begin{array}{l}\text { KLEIMAN, } \\
\text { KAUFFMANN, } \\
2006 ; \\
\text { KAUFFMANN } \\
\text { LEIVAS, } 2011\end{array}$ & $\begin{array}{l}\text { Revisão de Planos Diretores de diversas cidades brasileiras, coexistindo } \\
\text { com o recém-implementado Planejamento Estratégico. Multiplicam-se as } \\
\text { experiências em municípios brasileiros de aplicação da bacia hidrográfica } \\
\text { como unidade de planejamento integrado, buscando a correspondência das } \\
\text { divisões político-administrativas e dos planos urbanos com as bacias. Novos } \\
\text { e alternativos indicadores de sustentabilidade são formulados. }\end{array}$ \\
\hline
\end{tabular}


NORUS - v4, n.6, jul - dez 2016.

\begin{tabular}{|l|l|l|}
\hline & $\begin{array}{l}\text { CERQUEIRA, } \\
2012\end{array}$ & $\begin{array}{l}\text { Metodologias Alternativas de Desenvolvimento Urbano de Baixo Impacto } \\
\text { em Recursos Hídricos se disseminam em diversos países com efeitos no } \\
\text { Brasil. }\end{array}$ \\
\hline
\end{tabular}

Fonte: Elaborado com base em KAUFFMANN LEIVAS, 2011.

A evolução da aplicação do planejamento integrado à unidade bacia hidrográfica ilustra a crescente importância deste instrumento. Cabe destacar que os recursos hídricos de uma bacia hidrográfica são os alicerces para a sobrevivência e transformação do meio pelo homem, e também suas reservas para as futuras gerações. $\mathrm{O}$ recorte territorial adequado à gestão destes recursos é a bacia hidrográfica, âmbito em que se podem conciliar políticas setoriais de gestão do território e políticas setoriais do gerenciamento dos recursos hídricos, além de facilitar a integração equitativa de todos os usuários nos planejamentos (ALVIM, 2003; AFONSO, BARBOSA, 2005; KLEIMAN, KAUFFMANN, 2008).

As alterações provocadas pela ocupação humana, tais como o desmatamento, alteração e retificação dos cursos dos rios e a impermeabilização do solo especialmente quando realizada sem o adequado planejamento podem agravar em muito os processos erosivos, diminuir a capacidade de infiltração e aumentar o volume dos escoamentos superficiais, contribuindo para enchentes e inundações (HALL, 1984) que são especialmente identificáveis no âmbito das bacias. Vale ressaltar ainda que no modelo de gestão integrada, é no nível do município e do conjunto deles, que a aplicabilidade das políticas acontece, apesar da unidade de gestão ser a bacia hidrográfica. É fundamental, portanto, que as propostas de gestão da bacia levem em consideração sua relação com os sistemas de gestão que funcionam com outros limites, sobretudo os limites políticos administrativos (ALVIM, 2003) e, considerem a relação das sub bacias com as unidades de planejamento urbano definidas, por exemplo, pelos Projetos de Estruturação Urbana - PEUs, no caso do Rio de Janeiro (KAUFFMANN LEIVAS, 2011).

Vale destacar que a bacia hidrográfica (ou "bacia ambiental") pode ser identificada como sendo o "locus onde ocorrem as relações sociais de ordem cultural, política e econômica"; o território relativizado, de limites físicos "flexibilizados que privilegiam a dinâmica local, principalmente quando a abordagem de análise é direcionada para a área urbana enquanto ambiente antropizado" (AFONSO e BARBOSA, 2005, p. 15). Este espaço seria ainda palco privilegiado para a atuação dos agentes urbanos em suas lutas por direito à cidade ${ }^{8}$.

\footnotetext{
${ }^{8}$ Para Lefebvre (1968) o direito à cidade "é como um grito e uma demanda" através do qual os habitantes declaram a sua intenção de começar uma luta para controlar a produção do espaço urbano, sem o Estado e sem o capital. É a mais radical das visões políticas, profundamente marxista na rejeição do capitalismo e também profundamente anarquista em sua determinação em lutar contra o Estado e sua gestão do espaço. $\mathrm{O}$ direito à cidade implica necessariamente em autogestão espacial: os habitantes gerenciando o espaço para si.
} 


\section{Formulações teórico-metodológicas de planejamento urbano sob a inspiração de Henri Lefebvre}

A importância da adoção da unidade de planejamento bacia hidrográfica, além das considerações expostas, na perspectiva de concretização da gestão urbano, ambiental e de recursos hídricos integrada, com vistas à sustentabilidade, reside em seu papel estratégico de trazer a cidade à resiliência, situação de mediação entre a insustentabilidade e a sustentabilidade, à luz da interação dialética entre opostos (LEFEBVRE, 1983), identificável também por isto com o espaço social (LEFEBVRE, 1991) e ainda, potencialmente capaz de contribuir para a superação do atual quadro do planejamento urbano, especialmente sob inspiração no pensamento de Henri Lefebvre.

\section{A atualidade do pensamento de Henri Lefebvre}

Em síntese, o quadro da insustentabilidade urbana atual se caracteriza como contradição básica do planejamento urbano contemporâneo e enfrenta o desafio de equacionar tensões e opções entre premissas, muitas vezes contraditórias e excludentes. Da cidade insalubre e em desordem, passa-se à ordenada e bela; acrescenta-se a visão progressista que compartimenta o território em zonas; estas passam a se conflitar, um pouco depois, com a visão ampliada de cidade articulada em polos de atração do planejamento estratégico e; acrescentam-se ainda as dificuldades em articular o planejamento urbano ao ambiental e de recursos hídricos: opção desejável à construção da sustentabilidade urbana.

Ilumina esta dinâmica o pensamento de Henri Lefebvre (1983) possibilitando, já preliminarmente, uma alternativa à visão dicotômica que permeia a história do desenvolvimento das cidades. O movimento entre polos opostos, em interação dialética, inspirada em Hegel, descortina o caminho entre ideias opostas, em constante interação, não mais estanques nem no tempo, nem no espaço. A partir da contraposição e contradição de ideias, nesta contínua transformação, levando a novas ideias, neste processo de fluído devir, se inserem as mediações, os elementos facilitadores (os termos médios) capazes de fornecer condições à própria superação destas oposições. Já não há mais uma escolha entre uma ou outra, mas uma situação diferenciada, enriquecida de algo novo, com capacidades de lidar com as mudanças, explicitar as contradições, minimizar impactos negativos e continuar.

A aplicação desta teoria ao contexto do planejamento urbano pode favorecer a identificação do percurso entre oposições, entre o insustentável e o sustentável, em interação dialética: uma situação se relaciona reflexivamente com a outra e em constante transformação. Identificam-se também outras variantes presentes nas análises urbanas, passíveis de associação aos polos opostos, tais como o caráter local e o global, o absoluto e o relativo; a situação da cidade legal e a da ilegal; os riscos nas áreas frágeis e nas não frágeis, a integração e a não 
NORUS - v4, n.6, jul - dez 2016.

integração dos planejamentos urbano, ambiental e de recursos hídricos, bem como diversas outras condicionantes ambientais, sociais e políticas. Tais situações caminham então, à luz do pensamento de Lefebvre (1983), na direção de seu oposto e, com potencial de constante transformação e superação, em movimento especialmente favorecido com a intermediação do termo médio. Sempre em caminho de renovação e reflexão.

Relaciona-se, no caso, a bacia hidrográfica, conforme já comentado, a este importante papel de mediação, objetivamente por ser potencialmente eficaz na integração dos planejamentos e se oportunizando estrategicamente como espaço adequado à resiliência urbana (estado de constante transformação e superação), locus privilegiado às atividades sociais, espaço social (KAUFFMANN LEIVAS, 2011). Lefebvre (1991) lembra que o espaço traduz um conjunto de diferenças, é o locus de coexistência da pluralidade e das simultaneidades de padrões, de maneiras de viver a vida urbana.

Assim, longe de ser meramente um meio neutro, ou recipiente, de atividades sociais, este espaço torna-se um jogo e um meio para representações contraditórias e para estratégias sociais; é um mediador ativo (lidando com tensões, representações e práticas, intencionais ou não, já que é carregado com sinais e símbolos), produzido, apropriado e transformado na base de interesses conflitantes, valores e ideias (BUSQUET, 2013).

Este espaço urbano seria entendido então como uma síntese da dicotomia cidade-campo, um elemento resultante da interação dialética cidade-campo, a manifestação material e sócio espacial da sociedade urbano-industrial contemporânea estendida, virtualmente, por todo o espaço social, um espaço de superação: “O tecido urbano prolifera, estende-se, corrói os resíduos de vida agrária, [...] 'o tecido urbano', não designa, de maneira restrita, o domínio edificado nas cidades, mas o conjunto das manifestações do predomínio da cidade sobre o campo" (LEFEBVRE, 1970).

Lefebvre quando fala das leis do urbano, dialeticamente considera as negatividades implicando em positividades, e que a concepção do urbano, visa, também a reapropriação pelo ser humano, de suas condições no tempo, no espaço, nos objetos.

Nesta perspectiva, nesta nova forma de pensar o urbano e o planejamento, para além das dualidades expostas, pode-se caminhar na construção de novas formulações que ajudem a entender e superar os atuais entraves urbanos, utilizando-se inclusive estratégias e instrumentos de mediação, tais como a bacia hidrográfica, mas também novas ferramentas, inovadoras também na aplicação e na abordagem, tais como os indicadores. 


\section{Formulações teórico-metodológicas de planejamento urbano sob a inspiração de Henri Lefebvre}

\section{A cidade sob novas formulações}

Novas ferramentas podem ser muito úteis na proposição de formulações para planejamento urbano, com base no pensamento e metodologia de Henri Lefebvre, especialmente se relacionadas diretamente à área da bacia, tais como um instrumento de conexão forte, um indicador de ocupação sustentável da bacia hidrográfica (IOS-BH). Estes oportunizam o controle do crescimento urbano de forma sustentável e minimizam os efeitos nocivos das alterações destes parâmetros de forma desvinculada das características objetivas das bacias, conforme proposto em Kauffmann Leivas (2011).

Este indicador a ser incluído na legislação urbanística, novo elemento que incrementa o aspecto da bacia hidrográfica como termo médio na perspectiva metodológica de Lefebvre (1983), se constitui, ele mesmo, em também importante variante de mediação no movimento entre a insustentabilidade e a sustentabilidade urbana. O IOS-BH permite lidar com a contradição na compatibilização entre unidades estanques do planejamento funcionalista, o zoneamento, com a adoção da bacia hidrográfica como unidade de planejamento integrado. Este indicador se relaciona objetivamente com a área da bacia hidrográfica, mas concomitantemente se refere e tem em sua composição elementos diretamente relacionados também à área de planejamento: zoneamento ou divisões administrativas, que podem ser correspondidas a sub bacias. Destaca-se ainda que o indicador pode ser incorporado à legislação urbanística, estrategicamente concretizando e informando (publicamente) o estado ou estágio da ocupação sustentável (ou de resiliência) de determinada bacia ou sub bacia hidrográfica.

O esquema a seguir, Figura 1, ajuda a caracterizar o IOS-BH, em sua constituição teórica, que traz na sua formulação o conceito de interação de polos opostos, apontando para o seu potencial de mediação em lidar dialeticamente com contradições da insustentabilidade urbana, favorecendo a almejada contribuição para a superação do planejamento contemporâneo.

O IOS-BH inspirado na metodologia de Lefebvre (1983) se configura como termo de mediação e conexão (entre o planejamento integrado das águas urbanas e a sua unidade de gestão (bacia hidrográfica); entre esta e a legislação urbanística e; entre a legislação e o planejamento. O novo indicador (aplicado à legislação urbanística) de ocupação sustentável da bacia hidrográfica (unidade do planejamento integrado), fornece ainda um novo aporte teórico metodológico à construção de indicadores, tanto por sua composição teórica, quanto por sua constituição empírica. 
Figura 1. Constituição Teórica do Indicador de Ocupação Sustentável da Bacia Hidrográfica_IOS-BH

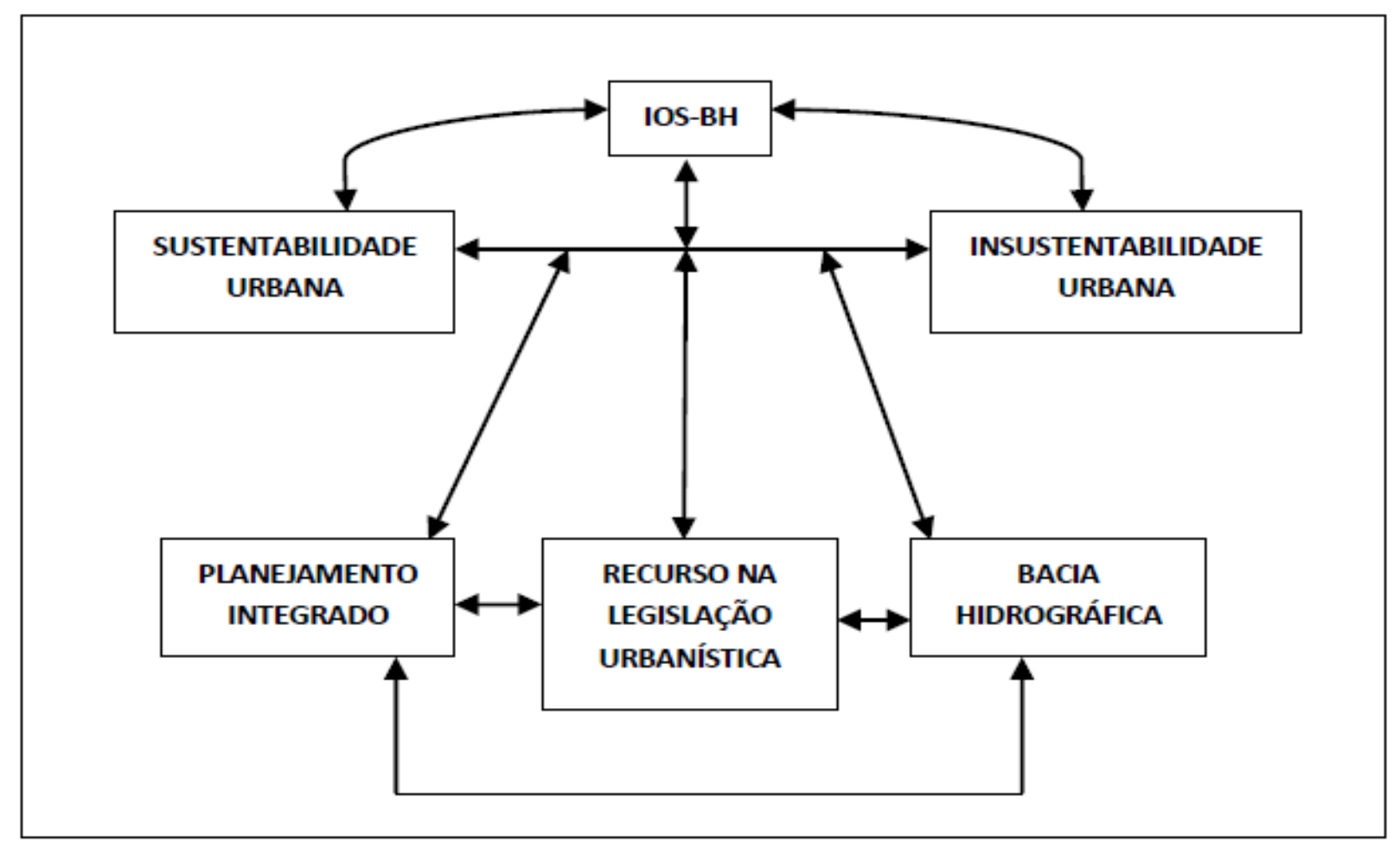

Fonte: KAUFFMANN LEIVAS, 2011.

Este instrumento (KAUFFMANN LEIVAS, 2011) incorpora no seu cálculo os diversos condicionantes físicos, sociais e culturais, especificidades muito propriamente relacionadas à bacia hidrográfica urbana, tais como: taxa de impermeabilização do solo (KAUFFMANN, 2003), disponibilidade de serviços de infraestrutura; condicionantes de clima, ventos e vegetação; densidade demográfica e edilícia; tipos de solo e de capacidade de absorção e escoamento de águas pluviais nos terrenos e outros. Tal proposição favorece ainda o acompanhamento ou controle do crescimento urbano, de forma mais sustentável, de acordo com critérios qualificáveis e quantificáveis, passíveis de discussões técnicas e objetivas, mas também de questionamentos e contribuições da população em geral. As possíveis alterações dos parâmetros urbanísticos e edilícios se passam então de forma divulgada, planejada, controlando ou minimizando os seus efeitos antrópicos negativos nas bacias, de acordo com os respectivos cálculos e projetos.

A taxa de impermeabilização do solo (TI) já se demonstrava, a partir de diversos estudos, inclusive em Kauffmann (2003), um excelente indicador de qualidade urbano-ambiental aplicável à bacia hidrográfica e especialmente indicado à verificação da qualidade das águas (SCHUELER, 1994). A possibilidade de se agregar a TI a outras variáveis já se configurava também como uma perspectiva importante. A disponibilidade de infraestrutura se corresponde 
Formulações teórico-metodológicas de planejamento urbano sob a inspiração de Henri Lefebvre

diretamente à população usuária e, portanto, às suas habitações e respectivas áreas construídas. A densidade de habitantes quantifica habitantes por área ocupada que, por sua vez se relaciona por contraposição à disponibilidade de áreas verdes e livres (comumente recomendada também por número de habitantes), ambas, estão relacionadas também aos impactos nas águas urbanas tanto por consumo como por degradação e impermeabilização dos solos das bacias (KAUFFMANN LEIVAS, 2011).

Configurou-se então, a partir destas variáveis, o IOS-BH, enriquecido, apresentado a seguir (Figura 2) em sua constituição empírica, buscando quantificar (em número) e qualificar (como indicador) o quanto a ocupação (por habitantes e área construída) de um terreno ou bacia hidrográfica é sustentável sob os aspectos da disponibilidade de áreas verdes e de serviços de infraestrutura, qualidade das águas e impermeabilização dos solos.

Figura 2. Constituição Empírica do Indicador de Ocupação Sustentável da Bacia Hidrográfica_IOS-BH

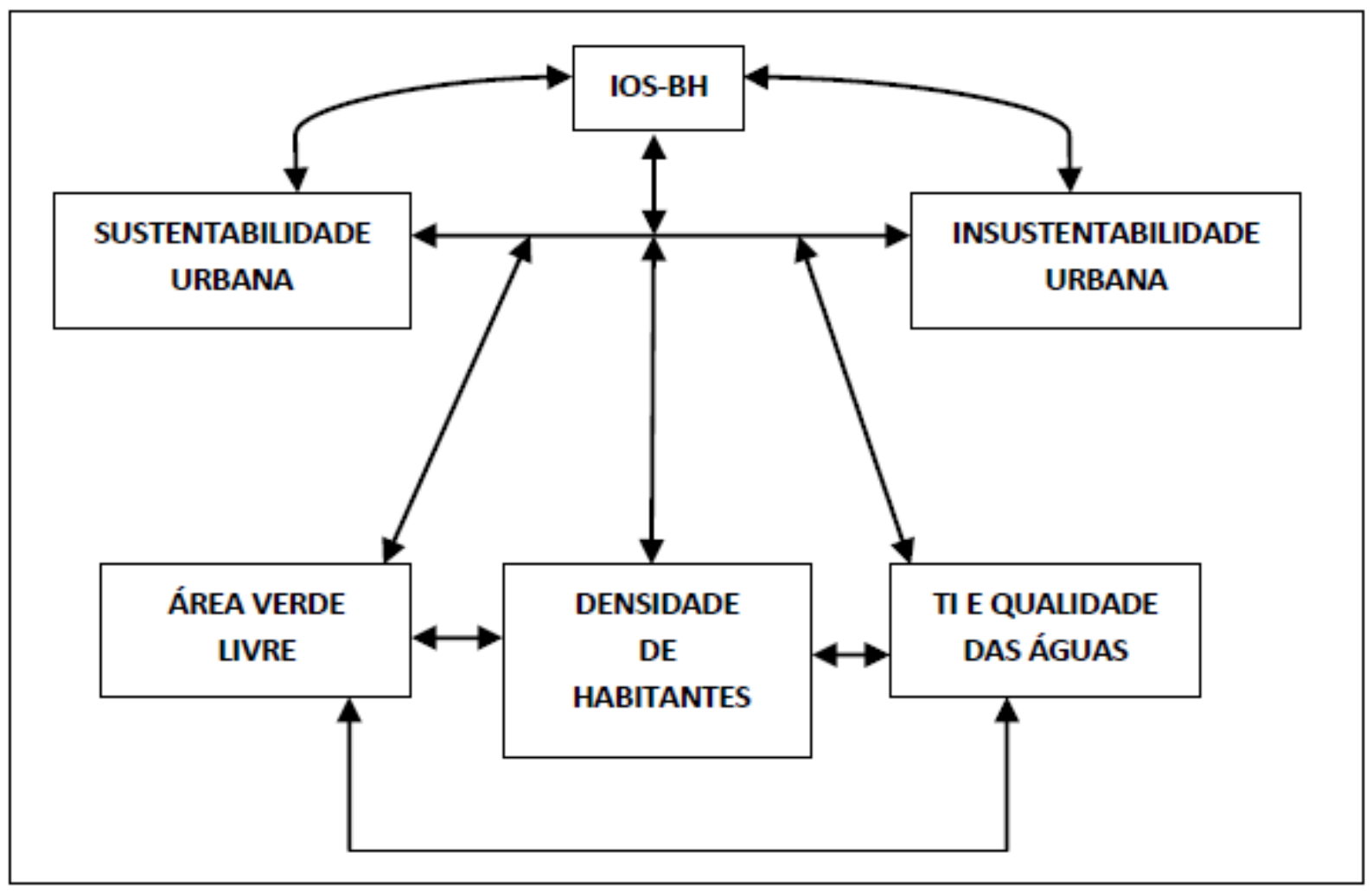

Fonte: KAUFFMANN LEIVAS, 2011.

O IOS-BH, simultaneamente um indicador de quantidade e qualidade, pode ser aplicado a bacias urbanas em geral, guardadas as suas especificidades. Aplicou-se o IOS-BH embacia experimental localizada na Barra da Tijuca, área de expansão da cidade do Rio de Janeiro, com resultados numéricos apropriados a partir da quantificação dos parâmetros: área verde livre; 
NORUS - v4, n.6, jul - dez 2016.

densidade de habitantes; TI e qualidade das águas, relacionados à referida bacia e desenvolvidos a partir das equações resultantes.

Esta apropriação do IOS-BH se mostrou qualificadaà análise regressiva e progressiva da ocupação urbana de bacias hidrográficas, oportunizando sim, a gestão das águas urbanas de forma integrada, através da forte conexão com a matriz bacia hidrográfica e com a legislação urbanística, informando e instrumentalizando a população, legisladores, técnicos e executores para as ações de um novo planejamento, que superado, pode sim, reverter o caminho para “Trantor” e, caminhar para a sustentabilidade (KAUFFMANN LEIVAS, 2011).

\section{Conclusão}

A questão da perda da qualidade de vida urbana, com ênfase nos grandes centros e nos países em desenvolvimento, já se inclui nas diversas discussões e proposições para problemas urbanos.

Com a inspiração no pensamento de Henri Lefebvre trazido no presente texto, tem-se a expectativa de contribuir para a formulação de um novo aporte teórico-metodológico às teorias de planejamento urbano e às formulações de indicadores de sustentabilidade urbana. Alternativas possíveis à dinâmica atual de planejar a cidade aqui consideradas, apontam potenciais estratégias de mediação e superação às principais dicotomias presentes no atual contexto de insustentabilidade.

Destacam-se entretanto importantes entraves à superação do planejamento urbano contemporâneo, ainda persistentes, especialmente em seus impactos mais diretos e negativos à qualidade de vida urbana. Consideram-se especialmente importantes as dificuldades na efetivação da integração dos planejamentos urbano, ambiental e de recursos hídricos, bem como a adoção da bacia hidrográfica como unidade do planejamento integrado e; a formulação de indicadores diretamente relacionados à bacia hidrográfica e que oportunizem a integração dos planejamentos.

E, na perspectiva de reversão desses descaminhos de insustentabilidade urbana e do seu instrumental, com inspiração em Lefebvre (1983), ressaltam-se a importância e o papel das mediações apresentadas. Podem-se destacar assim as novas estratégias de desenvolvimento urbano de baixo impacto potencialmente favoráveis à resiliência urbana; a bacia hidrográfica como unidade do planejamento integrado e; a introdução de novos indicadores de ocupação sustentável das bacias hidrográficas tais como o IOS-BH (KAUFFMANN LEIVAS, 2011).

Reafirma-se, por fim, a utilidade do termo médio, em especial o IOS-BH, que, fornecido pelo próprio método dialético a partir do movimento entre os opostos, pode representar uma 
Formulações teórico-metodológicas de planejamento urbano sob a inspiração de Henri Lefebvre

estratégia de superação das dicotomias predominantes no pensamento e planejamento dualistas contemporâneos; a partir do aprofundamento das contradições existentes, num processo de instrumentalização e construção do novo, enriquecido a cada movimento de superação, na continuidade da construção coletiva do conhecimento e de novas perspectivas para a cidade. Expectativas estas, incentivadas com as palavras de Lefebvre (2001, p.145) de que:

[...] a humanidade só levanta problemas que ela mesma pode resolver, escreveu Marx.
Atualmente, alguns acreditam que os homens só levantam problemas insolúveis.
Esses desmentem a razão. Todavia, talvez existam problemas fáceis de serem
resolvidos, cuja solução está aí, bem perto, e que as pessoas não levantam [...] Henri Lefebvre

\section{Referências}

AFONSO, A. S.; BARBOSA, F.P. A Bacia Ambiental como uma Nova Matriz Urbanística de Planejamento. In: 1ST INTERNATIONAL CONGRESS ON ENVIRONMENTAL PLANNING AND MANAGEMENT, Brasília, DF. Proceedings of 1st Congress of Environmental Planning and Management. Brasília: Universidade Católica de Brasília, 2005.

ALVIM, Angélica Tanus Benatti. A Contribuição do Comitê do Alto Tietê à Gestão da Bacia Metropolitana, 1994-2001. São Paulo. Tese (Doutorado). Faculdade de Arquitetura e Urbanismo, Universidade de São Paulo, 2003.

AZEVEDO, Ana Lucia. Cidades Verticais Geram Ilhas de Calor. O Globo. Rio de Janeiro, 21 abr. 2013.

BUSQUET, Grégory. L'espace Politique chez Henri Lefebvre: l'Ideologie et l'Utopie. [Espaço Político na Obra de Henri Lefebvre: Ideologia e Utopia]. Tradução: Sharon MOREN. Justiça Spatiale /Justiça Espacial, n.5, 2012/ 2013.

CARPENTER, Steve; WALKER, Brian; ANDERIES, J. Marty e ABEL, Nick. From Metaphor to Measurement: Resilience of What to What? Ecosystems, v. 8, n. 4, 2001.

CERQUEIRA, Luiz Fernando F. Redesenho Urbanístico de Assentamentos Informais com Vistas à Conservação da Água e Sustentabilidade Ambiental, Rio de Janeiro. Tese (Doutorado em Meio Ambiente). Universidade do Estado do Rio de Janeiro, 2012.

FREITAS RIBEIRO, V.de Moraes. A (Des)Construção do Espaço Carioca na 'Era Cesar Maia' (1993-2008): Reflexões sobre o Modelo de Planejamento Urbano Estratégico e o Conjunto de Objetos Arquitetônicos Denominado 'Pentágono do Milênio', Rio de Janeiro. Tese (Doutorado em Planejamento Urbano e Regional). Instituto de Pesquisa e Planejamento Urbano e Regional, Universidade Federal do Rio de Janeiro, 2009.

GUNDERSON, Lance H.; HOLLING, C. S. Panarchy: Understanding Transformations in Human and Natural Systems. Washington, D. C., Island Press, 2002.

IBGE, Instituto Brasileiro de Geografia e Estatística [Online], 2013. Disponível em: www.ibge.gov.br. Acesso: 08/05/2013. 
NORUS - v4, n.6, jul - dez 2016.

HALL, M.J. Urban Hydrology. Belfast, Ireland: Elsevier Ltd., 1984.

KAUFFMANN LEIVAS, Márcia O. Expansão Urbana e Qualidade de Vida: Proposta para Desenvolvimento de Indicadores de Sustentabilidade Aplicados à Legislação Urbanística, Rio de Janeiro. Dissertação (Mestrado em Engenharia Ambiental). Universidade do Estado do Rio de Janeiro, 2003.

Indicadores na Legislação Urbanística Carioca em Novas Formulações de Sustentabilidade Urbana: contribuição para o desenvolvimento de indicador de ocupação sustentável da bacia hidrográfica (IOS-BH), Rio de Janeiro. Tese (Doutorado em Planejamento Urbano e Regional). Instituto de Pesquisa e Planejamento Urbano e Regional, Universidade Federal do Rio de Janeiro, 2011.

KAUFFMANN LEIVAS, Márcia O.; KLEIMAN, Mauro. Superação do Planejamento Urbano Contemporâneo: apontamentos inspirados em Henri Lefebvre. LABOR\&ENGENHO, v. 7, n. 2, 2013.

KLEIMAN, Mauro; KAUFFMANN LEIVAS, Márcia O. Novos Parâmetros para Planos de Bacias Urbanas no Brasil. In: VI CONGRESSO IBÉRICO SOBRE GESTÃO E PLANEJAMENTO DA ÁGUA, Vitoria-Gasteiz. Anales del $6^{\circ}$ Congresso Ibérico sobre Gestão e Planejamento da Água. Zaragoza: Fundación Nueva Cultura del Agua, 2008.

KLEIMAN, Mauro; RIBEIRO, Viviani M.F.; MENDES, Victor M. de O. Aonde vamos? O Modelo Estratégico e suas Diferentes Abordagens de Política Urbana do Rio de Janeiro e Salvador. In: XII ENCONTRO DA ASSOCIAÇÃO PORTUGUESA PARA O DESENVOLVIMENTO REGIONAL, Viseu. Actas do $\mathbf{1 2}^{\circ}$ Encontro da Associação Portuguesa para o Desenvolvimento Regional. Coimbra: Associação Portuguesa para o Desenvolvimento Regional, v.1, p.38-40, 2006.

LEFEBVRE, Henri. Le Droit à la Ville. Paris: Anthropos, 1968.

La Révolution Urbaine. Paris: Gallimard, 1970.

Lógica Formal/Lógica Dialética. Tradução: Carlos Nelson Coutinho. (Coleção Perspectivas do Homem, v.100). $3^{\mathrm{a}}$ ed. Rio de Janeiro: Civilização Brasileira, 1983. (Original 1947).

The Production of Space. Oxford: Blackwell, 1991. (Original 1974).

. A Cidade do Capital. Tradução: Maria Helena Rauta Ramos e Marilene Jamur. $2^{\mathrm{a}} \mathrm{ed.}$ Rio de Janeiro: DP\&A, 2001.

MERRIFIELD, Andy. The Urban Question under Planetary Urbanization. International Journal of Urban and Regional Research, v.37(3), p.909-922, 2013.

MUMFORD, Lewis. La Cultura de las Ciudades. Tradução: Carlos Maria Reyles. Buenos Aires: Emecé Editores S.A.,1945.

POLETO, C. Suds. (Sustainable Urban Drainage Systems): uma Contextualização Histórica. Revista Thema, v.8, 2011. 
Formulações teórico-metodológicas de planejamento urbano sob a inspiração de Henri Lefebvre

SANTOS, Fernando Teigão dos. Territórios Resilientes enquanto Orientação de Planeamento. Prospectiva e Planeamento, v. 16, Lisboa, 2009.

SCHUELER, T.R. The Importance of Imperviousness. Watershed Protection Techniques, v.1, n.3, p.100-111, 1994.

SRHU/MMA. PRÊMIO. Boas Práticas em Sustentabilidade Ambiental Urbana. Brasília, Junho 2012.

WALKER, Brian; HOLLING, C.S.; CARPENTER, Sthepen R. e KINZIG, Ann. Resilience, Adaptability and Transformability in Social-Ecological Systems. Ecology and Society, v. 9, n. 2, art.5, 2004. 